\title{
Ambient aerosol size distributions and number concentrations measured during the Pittsburgh Air Quality Study (PAQS)
}

\author{
Charles O. Stanier, Andrey Y. Khlystov ${ }^{1}$, Spyros N. Pandis* \\ Department of Chemical Engineering, Carnegie Mellon University, 5000 Forbes Avenue, Pittsburgh, PA 15213-7139, USA
}

\begin{abstract}
Twelve months of aerosol size distributions from 3 to $560 \mathrm{~nm}$, measured using scanning mobility particle sizers are presented with an emphasis on average number, surface, and volume distributions, and seasonal and diurnal variation. The measurements were made at the main sampling site of the Pittsburgh Air Quality Study from July 2001 to June 2002. These are supplemented with 5 months of size distribution data from 0.5 to $2.5 \mu \mathrm{m}$ measured with a TSI aerosol particle sizer and 2 months of size distributions measured at an upwind rural sampling site. Measurements at the main site were made continuously under both low and ambient relative humidity. The average Pittsburgh number concentration $(3-500 \mathrm{~nm})$ is $22,000 \mathrm{~cm}^{-3}$ with an average mode size of $40 \mathrm{~nm}$. Strong diurnal patterns in number concentrations are evident as a direct effect of the sources of particles (atmospheric nucleation, traffic, and other combustion sources). New particle formation from homogeneous nucleation is significant on $30-50 \%$ of study days and over a wide area (at least a hundred kilometers). Rural number concentrations are a factor of 2-3 lower (on average) than the urban values. Average measured distributions are different from model literature urban and rural size distributions.
\end{abstract}

(C) 2004 Elsevier Ltd. All rights reserved.

Keywords: Number concentration; Aerosol size distribution; Urban air quality; Pittsburgh Air Quality Study; PAQS

\section{Introduction}

The size distribution of atmospheric aerosols, together with their composition, sources, and sinks, is a key element in understanding and managing aerosol effects on health, visibility, and climate. A number of epidemiological studies have shown adverse health effects of particulate matter (PM) including respiratory irritation and changes in pulmonary function as well as associations between particulate mass concentrations and mortality (Samet et al., 2000; Wichmann et al., 2000; Lippmann et al., 2000). Recently, there has been an

\footnotetext{
*Corresponding author.

E-mail address: spyros@andrew.cmu.edu (S.N. Pandis).

${ }^{1}$ Currently at Department of Civil and Environmental Engineering, Duke University, Box 90287, Durham, NC 27708, USA.
}

increased interest in the relative health effects of particles of smaller sizes (Oberdorster et al., 1992, 1995; Donaldson and MacNee, 1998). Some laboratory studies have also shown that for a given mass concentration, health effects are larger for smaller particle sizes (Wichmann and Peters, 2000). In addition, the particle size distribution is an important parameter for the estimation of the magnitude of direct and indirect aerosol-climate effects.

There have been many sampling efforts to measure aerosol size distributions in urban, rural, and remote sites around the globe, and nearly all field campaigns now include some measurements of aerosol size distributions. Some recent continental sampling campaigns that measured size distributions include the Atlanta PM Supersite program (Woo et al., 2001), and sampling campaigns in Los Angeles (Kim et al., 2002), Northern Europe (Ruuskanen et al., 2001), Tennessee (Cheng and Tanner, 2002), Brisbane, Australia (Morawska et al., 
2002), England (Harrison et al., 1999), Estonia and Finland (Kikas et al., 1996) and Central Europe (Birmili et al., 2001).

Most of these studies reported 24-h average number concentrations $(10-500 \mathrm{~nm})$ at continental sites ranging from around 5000-25000 $\mathrm{cm}^{-3}$ (Ruuskanen et al., 2001; Kim et al., 2002; Woo et al., 2001; Morawska et al., 2002). Sites that have monitored $3-10 \mathrm{~nm}$ particles find comparable numbers of particles in that size range relative to the $10-500 \mathrm{~nm}$ size range (Woo et al., 2001). Diurnal patterns vary between two extremes: (a) influenced predominantly by meteorology for sites without local particle sources or nucleation; and (b) strongly influenced by local sources such as traffic and nucleation (Kim et al., 2002; Morawska et al., 2002). Little has been reported regarding seasonal patterns in aerosol concentrations due to the lack of long-term monitoring.

Some parameterizations for model size distributions are available for urban and continental aerosols (Whitby, 1978; Jaenicke, 1993). Even if these parameterizations are widely used, their applicability to areas other than the ones for which they were developed has not been investigated.

This paper presents a statistical summary of size distributions measured during $1 \mathrm{yr}$ of continuous monitoring at the Pittsburgh Supersite during the Pittsburgh Air Quality Study (PAQS), forming one of the first longterm data sets for aerosol size distributions in the Northeastern United States. Aerosol size distributions from $3 \mathrm{~nm}$ to $2.5 \mu \mathrm{m}$ were monitored for over 15 months at the central sampling site of the study. Aerosol size distributions were measured at low relative humidity, and at ambient relative humidity to assess the impact of aerosol water on the PM size distribution. Additional aerosol size distributions were collected at an upwind location for approximately 2 months to assess the difference between rural and urban PM size distributions in the airshed. The wide size range, long-term (more than a year) deployment, rural/urban comparison, and dual relative humidity sampling provide advantages in using the size distribution data set to understand and quantify atmospheric aerosol formation, processes, and exposure.

Statistical averages, diurnal and seasonal trends for the urban location, and local sources of particles are discussed. These results are compared to size distributions measured continuously for 6 weeks at a rural site upwind of Pittsburgh to assess the spatial variability and impact of the urban sources on the PM number distribution. While size-resolved aerosol chemistry is not discussed in this work, it was addressed as part of the PAQS. The key findings are summarized in the Results and discussion section, based on Cabada et al. (2004). Finally, the measurement results are compared to other similar investigations and to model size distributions.

\section{Experimental}

The main sampling location was in a park $5 \mathrm{~km}$ east (downwind) of downtown Pittsburgh. Two scanning mobility particle sizer (SMPS) systems (TSI 3936L10 and TSI 3936N25) were operated at the main location continuously from July 2001 to July 2002. These instruments measured the size distribution of particles from 3 to $600 \mathrm{~nm}$. These were augmented by a TSI aerosol particle sizer (APS) 3320 measuring from 0.5 to $20 \mu \mathrm{m}$ for the first 3 months of the sampling period and a TSI APS 3321 measuring in the same size range for the final 2 months of the sampling period. Aerosol measurements at the main site were made at both low relative humidity and ambient relative humidities to assess the importance of relative humidity to the size distribution. This combination of three sizing instruments with RH control, called the dry-ambient aerosol size spectrometer (DAASS) is described in Stanier et al. (2004a). Another SMPS system (TSI 3071/3010) was located at a rural site in Florence, Pennsylvania, $38 \mathrm{~km}$ west (mostly upwind) of the city during 2002. At the Florence site, the aerosol size distribution was measured at slightly sub-ambient relative humidity.

The urban sampling site was relatively far from local sources of primary particles. The nearest major city street was $0.5 \mathrm{~km}$ away, and the nearest highway was $1.1 \mathrm{~km}$ away. Small local sources included the nearby Carnegie Mellon University campus and a local coalfired steam plant that was approximately $1 \mathrm{~km}$ away from the site.

Each of the three sizing instruments acquired an aerosol size distribution eight times per hour, with four of these using the low relative humidity channel, and four of them using the ambient relative humidity inlet. The raw data, and associated temperature and relative humidity information, were acquired using a PC and then processed afterward. Data processing consisted of inversion of the raw size distributions using the TSI SMPS program (version 3.2) and the TSI Aerosol Instrument Manager Program (version 4.3) and corrections for inlet losses and counting efficiencies (see Stanier et al., 2004a, for additional discussion). The size distributions from the individual instruments were then merged into a single size distribution by using the nanoSMPS data through $30 \mathrm{~nm}$, the SMPS data from 30 to $600 \mathrm{~nm}$, and the APS data above $600 \mathrm{~nm}$. The algorithm of Khlystov et al. (2004a) was used to account for the inherent difference between the mobility size measured by the SMPS instruments and the aerodynamic size measured by the APS. The size distributions reported here are a function of mobility diameter for sizes below $600 \mathrm{~nm}$ and as a function of estimated mobility diameter for sizes above $600 \mathrm{~nm}$.

Extensive quality assurance checks were performed prior to instrument deployment and during the field 
study. Pre-study tests are described in Stanier et al. (2004a) and include various counting and sizing precision and accuracy checks using monodisperse aerosols. During the study, a schedule of maintenance activities was adhered to, including daily, weekly, and monthly equipment inspections focusing on maintenance of dry butanol in condensation particle counters, leak checks, and flow calibration.

After initial data reduction, two levels of data validation were performed. The first level focused on internal consistency of the size distribution data between the three instruments that made up the DAASS system, while the second looked for consistency between the DAASS system and other instruments, particularly those that provided continuous measurements of aerosol mass such as the TEOM (Tapered Element Oscillating Microbalance, Rupprecht and Patashnick, Albany, NY). The TEOM is a continuous particulate mass monitor that operated at the PAQS (Wittig et al., 2004) with a sample equilibration system (Meyer et al., 2000) to reduce the interference of water vapor on the sample while retaining as much semivolatile mass as possible. During validation, a small portion of the data was flagged as invalid. Values used for data reduction (sheath and aerosol flowrates and CPC counting efficiencies) were occasionally modified to maintain instrument-to-instrument precision, typically by $\pm 20 \%$ or less. A detailed data quality statement containing the list of corrections (as well as the measured size distributions) is available online in the NARSTO data archive (Stanier, 2003). The data reduction parameters were modified by first examining the time series of the ratio of aerosol mass (TEOM $\mathrm{PM}_{2.5}$ ) to aerosol volume as measured by the SMPS $(30-560 \mathrm{~nm})$, checking particularly for shifts in the ratio corresponding to maintenance (e.g. replacement of sheath blowers, CPCs, and dryers). No significant step changes were found in this ratio throughout the study. Two sets of CPC counting efficiencies (differing by about $15 \%$ for sizes below $30 \mathrm{~nm}$ ) were used for the two different CPC 3010 detectors used during the study. Adjustments to the
UCPC flowrate (and therefore the concentration of particles measured by the nano-SMPS) were required during four separate periods from January 2002 to May 2002 to force agreement in number concentration measured by nano-SMPS and SMPS from 15 to $60 \mathrm{~nm}$. The deviations were most likely caused by poor performance of the NDMA sheath and bypass blowers during this period. The cycling between low and ambient relative humidity caused a higher frequency of failures in sizing equipment than is typical in long-term sampling using SMPS, APS, and optical particle counters.

\section{Results and discussion}

The results are divided into several sections, including (a) summary statistics, (b) size-resolved chemical composition, (c) temporal (seasonal and diurnal) trends, (d) rural versus urban distributions, (e) sources of particles, and (f) comparison to other distribution measurements.

\subsection{Summary statistics}

The grand average number distribution measured during the PAQS (Fig. 1) has a number mode at $40 \mathrm{~nm}$ and a particle count of $22,000 \mathrm{~cm}^{-3}$. The corresponding surface area and volume distributions, calculated from the number distribution assuming spherical particles, are also shown in Fig. 1. The small discontinuity in the surface area and volume distributions are at the point where the SMPS and APS distributions are merged together. These are merged using a procedure described by Khlystov et al. (2004a). The merging procedure removes discontinuities almost completely in the number distribution, but not necessarily in the surface and volume distributions. After the merging procedure, the aerosol mass (TEOM $\mathrm{PM}_{2.5}$ ) and dried aerosol volume through $2.5 \mu \mathrm{m}$ were well correlated $\left(R^{2}\right.$ of 0.95 using a density of $1.52 \mathrm{~g} \mathrm{~cm}^{-3}$ ).

Various descriptive statistics regarding the measured size distributions are included in Table 1. Key points
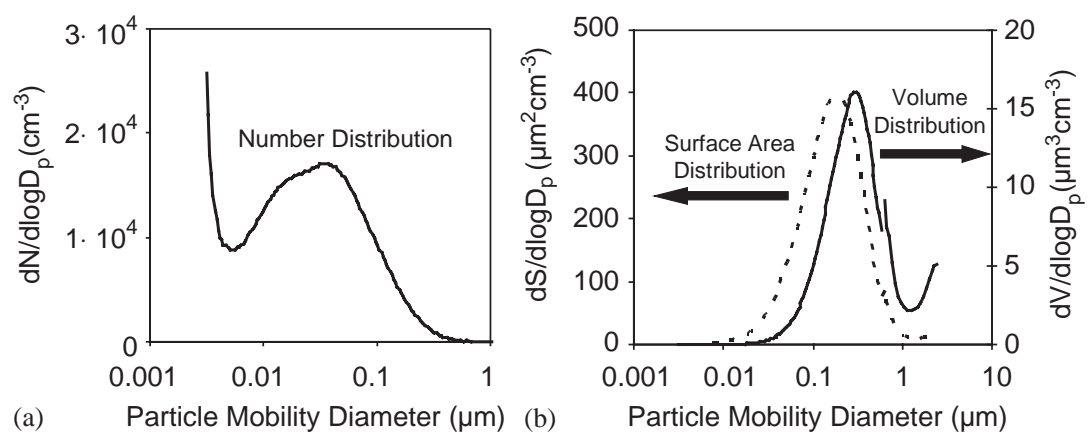

Fig. 1. Grand average (a) number, and (b) surface area and volume distributions from the PAQS (1/7/2001-30/6/2002). 
Table 1

Descriptive statistics of PM size distributions measured during the PAQS (size range $3 \mathrm{~nm}-2.5 \mu \mathrm{m}$ )

Attributes of distributions - grand average for PAQS main site (1/7/2001-30/6/2002)

\begin{tabular}{|c|c|c|c|}
\hline Distribution & Integral & Units & Mode \\
\hline Low $\mathrm{RH}^{\mathrm{a}}$ Number & 22,100 & $\mathrm{~cm}^{-3}$ & 40 \\
\hline Low RH Surface Area & 315 & $\mu \mathrm{m}^{2} \mathrm{~cm}^{-3}$ & 209 \\
\hline Low RH Volume & 11.5 & $\mu \mathrm{m}^{3} \mathrm{~cm}^{-3}$ & 322 \\
\hline Ambient $\mathrm{RH}^{\mathrm{b}}$ Number & 24,500 & $\mathrm{~cm}^{-3}$ & 45 \\
\hline Ambient RH Surface Area & 417 & $\mu \mathrm{m}^{2} \mathrm{~cm}^{-3}$ & 216 \\
\hline Ambient RH Volume & 18.3 & $\mu \mathrm{m}^{3} \mathrm{~cm}^{-3}$ & 414 \\
\hline
\end{tabular}

Descriptive statistics, 24-h averaged $\mathrm{cm}^{-3}$ (low RH channel only)

\begin{tabular}{lllcrrr}
\hline Size bin & Samples & Mean & Median & Min & Max & Standard deviation \\
\hline $3-10 \mathrm{~nm}$ & 307 & 5600 & 4900 & 1380 & 25,000 & 3200 \\
$10-20 \mathrm{~nm}$ & 307 & 4100 & 4100 & 1210 & 8800 & 1420 \\
$20-50 \mathrm{~nm}$ & 336 & 6500 & 6100 & 1880 & 14,000 & 2590 \\
$50-100 \mathrm{~nm}$ & 327 & 3600 & 3400 & 910 & 9700 & 1570 \\
$100-200 \mathrm{~nm}$ & 327 & 1710 & 1510 & 450 & 4550 & 790 \\
$200-500 \mathrm{~nm}$ & 327 & 460 & 361 & 64 & 1632 & 300 \\
$0.5-1 \mu \mathrm{m}$ & 102 & 18 & 11 & 1 & 67 & 17 \\
$1-2.5 \mu \mathrm{m}$ & 103 & 0.59 & 0.56 & 0.10 & 1.5 & 0.27 \\
\hline
\end{tabular}

${ }^{a}$ Low relative humidity distributions were measured at an average relative humidity of $14 \%$.

${ }^{\mathrm{b}}$ Ambient relative humidity distributions were measured at an average relative humidity of $58 \%$.

from Table 1 include (a) the significant difference in surface area and volume between the low RH (14\%) and ambient RH ( $58 \%$ on average) channels of the instrument, (b) the fact that $25 \%$ of the aerosol number is less than $10 \mathrm{~nm}$ and $75 \%$ of the aerosol number is less than $50 \mathrm{~nm}$ in size, and (c) the relatively good data recovery for the SMPS instruments which operated up to $560 \mathrm{~nm}$ $(84-92 \%)$ and relatively poor data recovery for the APS which operated from 0.5 to $2.5 \mu \mathrm{m}(28 \%)$. The APS was removed for service for upgrading and repair early in the study, and not returned to service until late in the study.

Hourly averaged number concentrations from the DAASS are compared in Fig. 2 to hourly averaged $\mathrm{PM}_{2.5}$ values from the TEOM. The highest number concentrations were observed during relatively clean days when the $\mathrm{PM}_{2.5}$ concentrations were less than $25 \mu \mathrm{g} \mathrm{m}^{-3}$. The number concentration is not positively correlated with the mass concentration and there is evidence of a negative correlation.

\subsection{Size-resolved chemical composition}

Measurements of size-resolved aerosol composition taken during the PAQS and reported in Cabada et al. (2004) are summarized here to provide context for interpretation of the size distribution measurements. Average $\mathrm{PM}_{2.5}$ concentrations were $20 \mu \mathrm{g} \mathrm{m}^{-3}$ in summer and $12 \mu \mathrm{g} \mathrm{m}^{-3}$ in winter. The average $\mathrm{PM}_{2.5}$ mass composition in summer (July intensive period) was dominated by sulfate $(\sim 40 \%)$ with significant contribu-

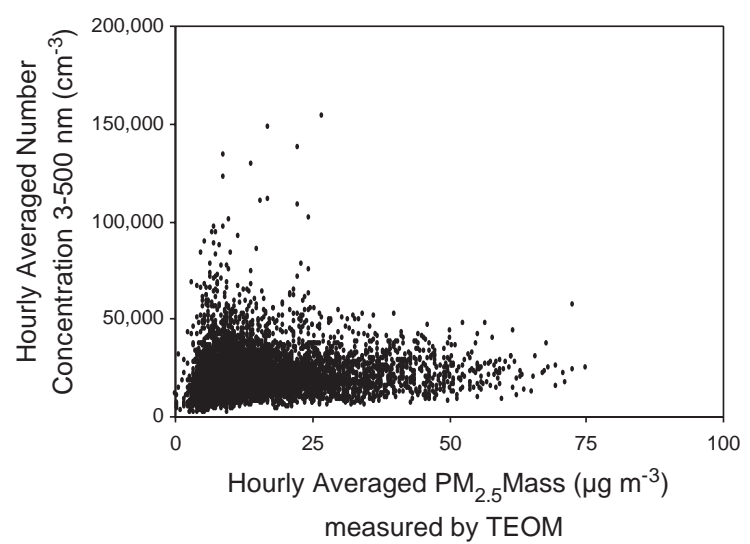

Fig. 2. Aerosol mass versus aerosol number for the PAQS. Hourly average values from the TEOM (mass) are plotted against hourly number integrals from 3 to $500 \mathrm{~nm}$ measured by SMPS.

tions from organic matter $(\sim 30 \%)$ and ammonium $(\sim 15 \%)$ with the balance being made up of elemental carbon, crustal elements, and nitrate. During summer, the sulfate and nitrate had a bimodal mass distribution, with a larger peak at around $0.7 \mu \mathrm{m}$ (from cloud processing) and a smaller peak at around $0.2 \mu \mathrm{m}$. Organic matter and elemental carbon were widely distributed throughout the mass distribution, with geometric mean diameter of $0.3 \mu \mathrm{m}$. During winter, the relative importance of nitrate $(\sim 20 \%)$ and organics 
$(\sim 35 \%)$ increased, while that of sulfate decreased $(\sim 30 \%)$. The mass distribution of the inorganic compounds (sulfate, ammonium, and nitrate) was similar, and showed the same bimodal behavior as the sulfate and ammonium in summer.

Ultrafine chemical composition was also studied by Cabada et al. (2004) and showed a significant seasonal change. Ultrafine $(<100 \mathrm{~nm})$ mass was about $0.6 \mu \mathrm{g} \mathrm{m}^{-3}$ during both summer and winter, making up less than $5 \%$ of the total $\mathrm{PM}_{2.5}$, but representing $90 \%$ of the particle number concentration. The summer ultrafine mass composition was $45 \%$ organic matter and $40 \%$ salts of ammonium and sulfate. During winter, the organics increased to $55 \%$ while the sum of ammonium and sulfate decreased to $35 \%$. This shift is probably caused by higher summertime levels of photochemical activity for oxidation of $\mathrm{SO}_{2}$, and increased wood burning and vehicular organic contributions in wintertime.

\subsection{Temporal trends}

While the aerosol size distributions (especially the number distribution) can exhibit significant variability on the sub-hourly, hourly, and even daily timescales, the monthly average distributions are relatively stable. Figs. 3 and 4 show monthly trends in properties of the size distributions for the low relative humidity and ambient relative humidity instrument channels, respectively. Fig. 3a shows the number mean diameter, surface mode diameter, and volume mode diameter for each month. The monthly averaged number mean diameter was relatively constant, varying from 39 to $52 \mathrm{~nm}$ without a consistent pattern. In contrast, the surface area and volume mode diameters show a clear summer maximum and winter minimum. This behavior is consistent given the summer peak in aerosol volume (and mass) in the Eastern United States. Fig. 3b shows the absence of a clear seasonal trend in average particle number in three different size ranges, while Fig. $3 \mathrm{c}$ shows the strong summertime maximum in aerosol volume, with summer values approximately twice winter levels.

Differences in the ambient and low relative humidity distributions can be seen by comparing Figs. 3 and 4 . While there is negligible difference in ambient and low relative humidity particles counts and number mean diameter, there are significant increases in the surface and volume integrals and mode diameters. For example, the volume mode diameter during summer months (July and August 2001 plus June 2002) was, on average
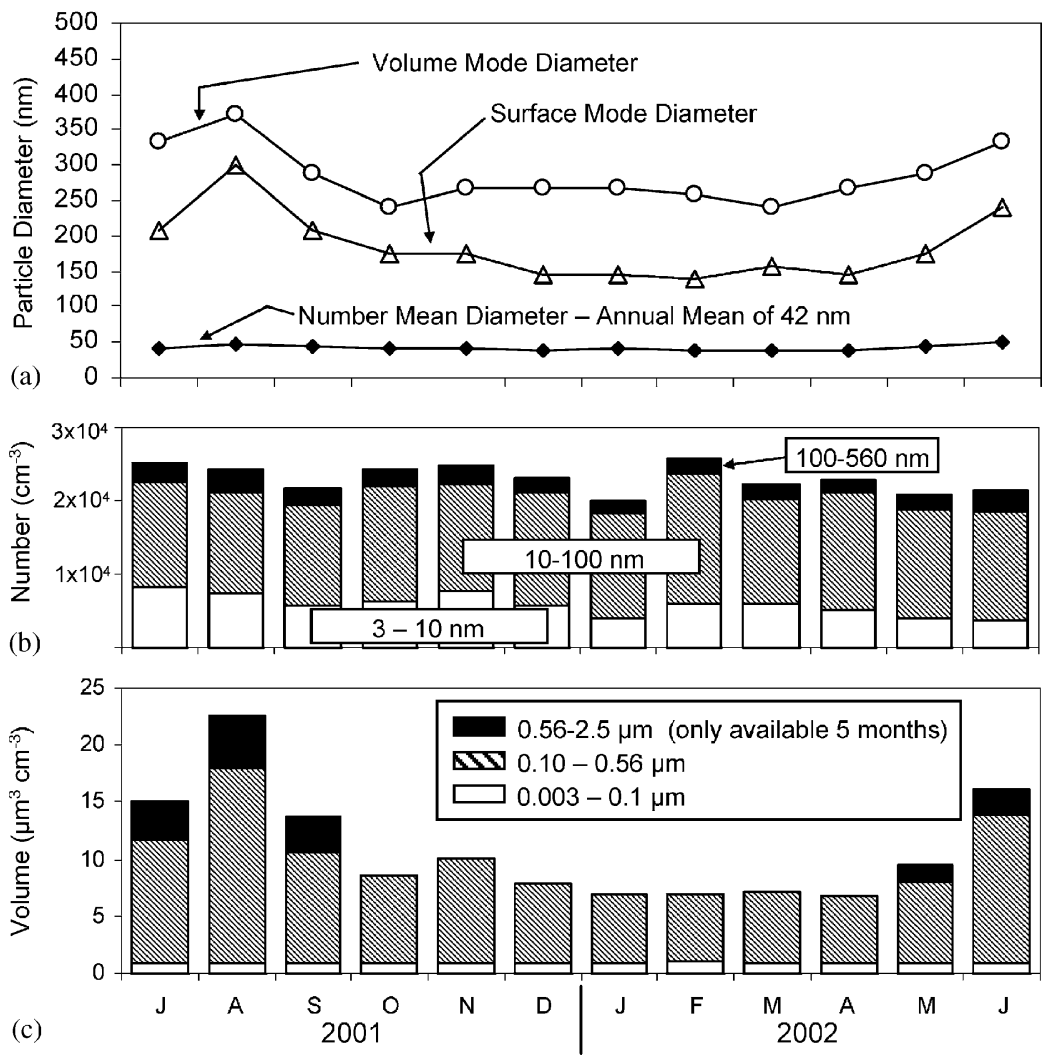

Fig. 3. Monthly patterns in (a) number, (b) surface, and (c) volume distributions for low relative humidity size distributions. 

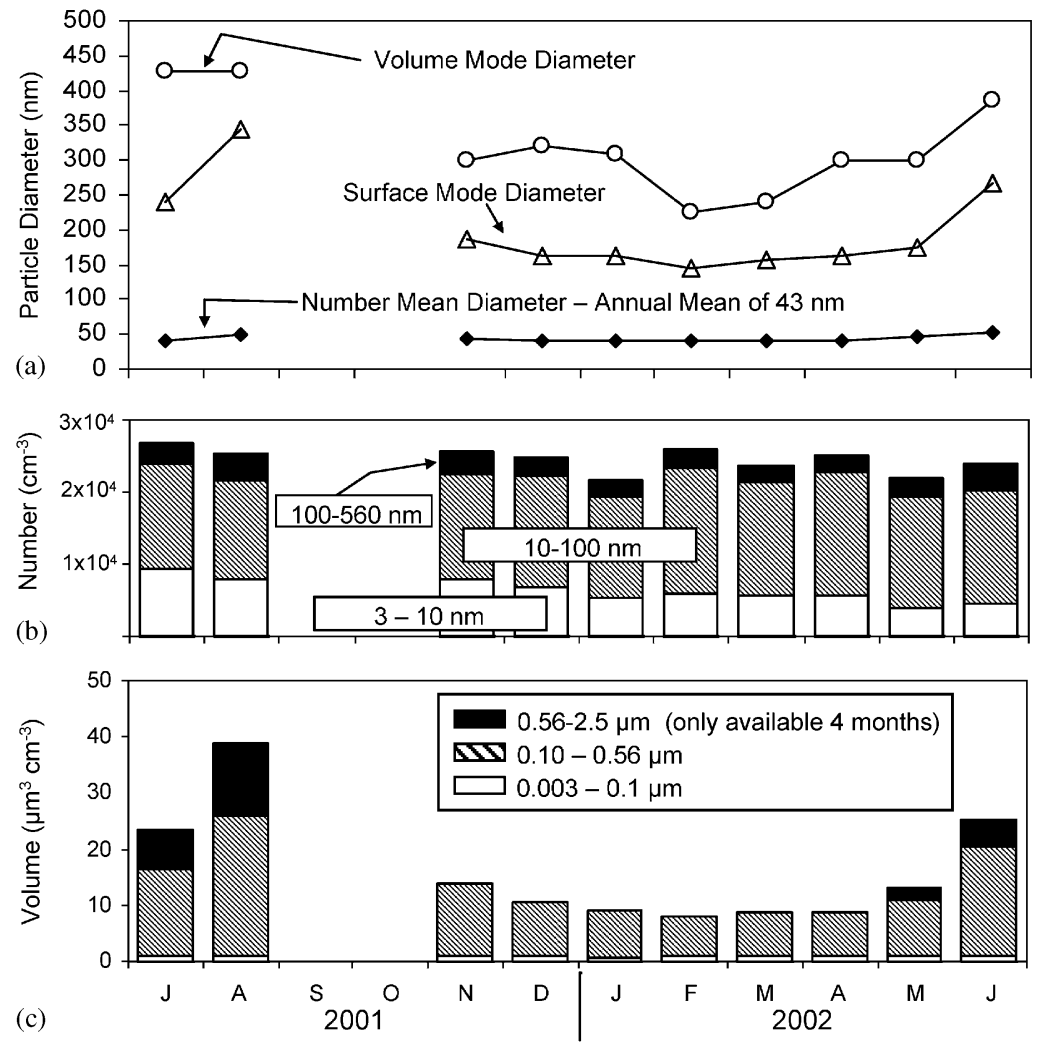

Fig. 4. Monthly patterns in (a) number, (b) surface, and (c) volume distributions for ambient relative humidity size distributions. The DAASS operated in the low relative humidity mode only during September and October 2001.

$415 \mathrm{~nm}$ for the ambient channel and $332 \mathrm{~nm}$ for the low relative humidity channel. The corresponding diameters for winter were $286 \mathrm{~nm}$ for the ambient channel and $256 \mathrm{~nm}$ for the low relative humidity channel. This corresponds to average water content of $38 \%$ (by volume) in measured samples during summer and $23 \%$ (by volume) during winter and average diameter growth factors of 1.16 and 1.09 , respectively. The average ambient summer and winter relative humidities were similar (around 60\%) and therefore the difference in water content is due primarily to seasonal differences in aerosol chemistry. During summer, the higher fraction of inorganic materials in $\mathrm{PM}_{2.5}$, the higher aerosol acidity, and higher levels of water soluble organics increased hygroscopicity and limited crystallization (Khlystov et al., 2004b), leading to higher measured aerosol water contents. These changes in the size distribution due to water uptake need to be considered for chemical and physical processes that rely on aerosol surface area, volume, and chemical composition, including visibility degradation and heterogeneous reactions. The values reported here are difficult to compare to other locations because there are no instances in the literature where simultaneous long-term dried and ambient size distributions are reported.

While seasonal trends were most apparent in the aerosol volume distribution, strong diurnal trends were observed in the aerosol number distribution. The diurnal pattern of aerosol number, averaged over the entire study, is shown in Fig. 5a. The solid line at the top of the figure is the diurnal pattern for total aerosol number, while the other lines in the figure show the diurnal pattern for specific size classes of aerosols, ranging from the nuclei mode $(3-10 \mathrm{~nm})$ up to part of the accumulation mode $(50-100 \mathrm{~nm})$. Figs. $5 \mathrm{~b}$ and $\mathrm{c}$ plot diurnal patterns for specific types of days, rather than for the average day of the entire study. Circled numbers refer to specific diurnal features discussed below in the text.

Total aerosol number, on average, peaked at midday (Fig. 5a-feature 1). Another feature apparent in the grand average diurnal trend is the minimum in $3-20 \mathrm{~nm}$ particles during the early morning, when their sources are at a minimum (Fig. 5a-feature 2). Also apparent is the drop in concentration of $50-100 \mathrm{~nm}$ particles from dilution during the morning when the mixing height is rapidly rising (Fig. 5a-feature 3). 


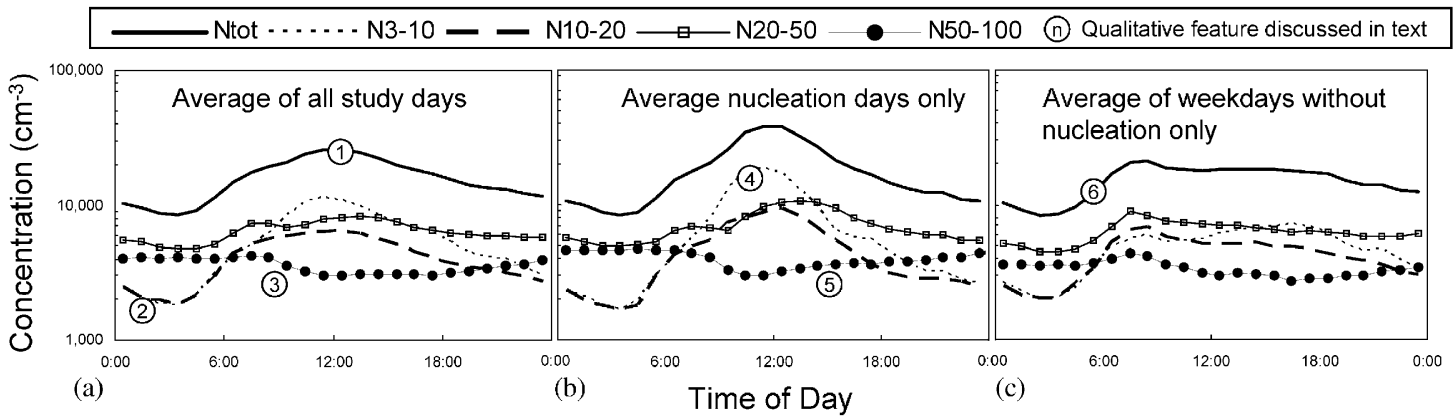

Fig. 5. Diurnal patterns in particle number (a) average of all study days, (b) average of all study days with regional nucleation, and (c) average of all weekdays without significant nucleation, showing influence of traffic. Numbered circles refer to qualitative features discussed in the text. The solid line at top of each profile is the total number, while the other lines are diurnal profile for specific size classifications. The smallest bin plotted is from 3 to $10 \mathrm{~nm}$ while the largest bin plotted is from 50 to $100 \mathrm{~nm}$.

Two of the most representative types of days, in terms of diurnal aerosol size distribution behavior, were days with in situ nucleation and days with a morning rush hour (weekdays) but no apparent nucleation. The former (regional nucleation) occurred on $30 \%$ of the study days and the average diurnal profile of these days is plotted in Fig. 5b. The latter (weekday without nucleation) also occurred on approximately $30 \%$ of the study days, and is plotted in Fig. 5c. Key features of the nucleation diurnal profile include the midday peak in nuclei mode $(3-10 \mathrm{~nm})$ particles (Fig. 5b-feature 4) as well as the slow growth in the number of $50-100 \mathrm{~nm}$ particles during the afternoon as the small particles created earlier in the day grow to larger sizes by coagulation and condensation (Fig. 5b-feature 5). An important feature of the non-nucleation weekday profile is the increase in particle number during the morning rush hour (Fig. $5 \mathrm{c}$ - feature 6). This feature can also be seen in the grand average diurnal profile (Fig. 5a) as a shoulder peak a few hours before the maximum from nucleation. Fig. 5c also shows that there is no afternoon rush hour peak and no midday peak. The former is because the afternoon rush hour is more spread out in time than the morning rush hour, and the mixing height is high during the late afternoon, diluting the emissions. The latter is because the midday peak is primarily from nucleation.

\subsection{Rural Versus urban distributions}

During February and March of 2003, an SMPS system sampled size distributions at a rural site (Florence, PA) $38 \mathrm{~km}$ upwind from the main sampling site. This provided information on the contribution of background aerosols, the spatial homogeneity of aerosol processes (e.g. new particle formation from in situ nucleation), and the difference between the "rural" and "urban" size distributions in the Pittsburgh area. For

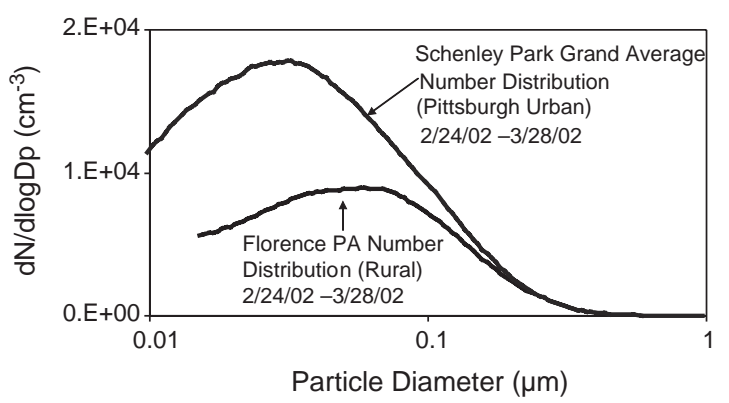

Fig. 6. Average number size distributions from the rural site (Florence, PA) and the urban site (Schenley Park, Pittsburgh, PA).

the remainder of this work, the main site results will be referred to as urban and the Florence site will be referred to as rural. The average size distributions measured during February and March (Fig. 6) show that number concentrations were, on average, 2-3 times higher at the urban site. Furthermore, the rural site had a larger mode size (approximately 62 versus $32 \mathrm{~nm}$ at the urban site). There was little difference in the number distributions above $200 \mathrm{~nm}$, consistent with the regional nature of the fine $\mathrm{PM}$ in the area and the similar $\mathrm{PM}_{2.5}$ mass concentrations measured at the two sites during the study. The rural site was impacted by nucleation very similarly to the urban site (Stanier et al., 2004b), but was not impacted nearly as strongly by traffic. Therefore, the diurnal patterns at the rural site were not as pronounced.

\subsection{Sources of particles}

Nucleation and vehicle emissions were the most important sources of particles impacting the main (urban) sampling site. Fig. 7 shows the evolution of the number size distribution on 2 consecutive days. The 
first day (10 August; top panel) does not exhibit nucleation behavior, while the second day (11 August; bottom panel) does. At 9 AM, there is significant new particle formation on 11 August. The frequency,

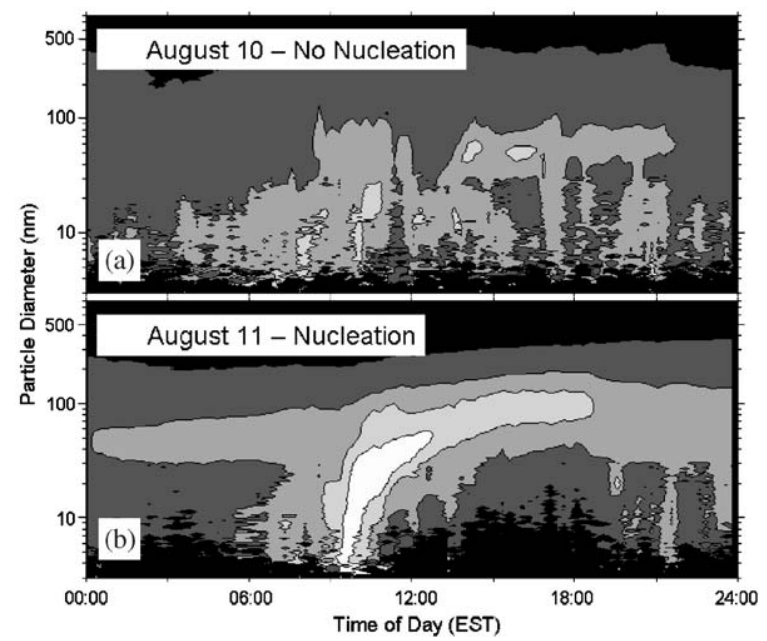

Fig. 7. Evolution of particles size distributions on a day without nucleation (10 August) and a day with nucleation (11 August). The plots show instrument response $\left(\mathrm{d} N / \mathrm{d} \log D_{\mathrm{p}}\right.$ with units of $\mathrm{cm}^{-3}$ ) over all size channels. Light colors are highest number concentrations and dark colors are the lowest number concentrations. Contour lines drawn at $\mathrm{d} N / \mathrm{d} \log \mathrm{D}_{p}$ values of $10^{2}, 10^{3}, 10^{4}, 10^{4.5}$, and $10^{5} \mathrm{~cm}^{-3}$.

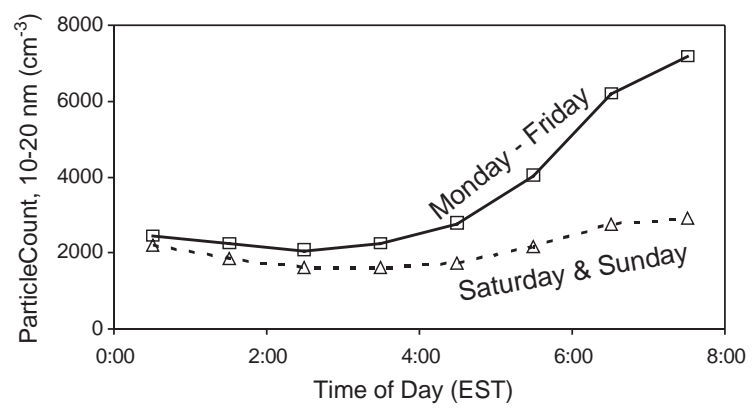

Fig. 8. Traffic as a source of particles. Ten to twenty nanometer particle count as function of time for weekends and weekdays at the urban site. intensity, meteorology, and possible chemistry of such new particle formation has been analyzed (Stanier et al., 2004b), showing that the nucleation events are associated with photochemical sulfuric acid production and occur on approximately $30 \%$ of the study days. The same type of behavior has also been witnessed in St. Louis (Shi, 2003).

The other major particle source impacting the urban site is traffic. On weekdays, there was a pronounced increase in particle concentrations for particles primarily in the size range from 3 to $30 \mathrm{~nm}$ (Fig. 8) beginning at approximately 04:00 EST. On weekends, the increase was much smaller and later in the morning. A similar analysis for daytime traffic is complicated by changes in the mixing height and nucleation activity.

\subsection{Comparison with other distribution measurements}

It is useful to compare the PAQS size distribution measurements to (a) other studies and (b) commonly used "typical" or model size distributions (Whitby, 1978; Jaenicke, 1993). Comparison to the sampling study of Ruuskanen et al. (2001) in three Northern European cities shows very similar results for aerosol number concentration (Table 2).

The comparison with model distributions of Whitby and Jaenicke is shown in Fig. 9, with number distributions in Fig. 9a and volume distributions in Fig. 9b. The model distributions used are Whitby's "urban average" distribution (labeled C-W1), Whitby's “average background" distribution (labeled C-W2), and Jaenicke's rural continental distribution (labeled C-J). Not shown in the figure is Jaenicke's urban distribution, which is very similar to Whitby's urban average distribution. The most general conclusion is that none of the model distributions fit either the urban or rural results from this study well. The model urban size distributions have an order of magnitude higher particle concentrations, with a strong $15 \mathrm{~nm}$ mode not seen in the average distributions from Pittsburgh. The model urban distributions are more appropriate for sites close to (<approximately $100 \mathrm{~m}$ ) to traffic or Los Angeles. Based on these results, it is recommended that caution be exercised in using model distributions.

Table 2

Comparison to other size distribution measurement campaigns

\begin{tabular}{llcl}
\hline Location & Number concentration $\left(\mathrm{cm}^{-3}\right)$ & Source \\
\cline { 2 - 4 } & $10-100 \mathrm{~nm}$ & $100-500 \mathrm{~nm}$ & Ruuskanen et al. (2001) \\
\hline Alkmaar, Netherlands & 18,300 & 2120 & Ruuskanen et al. (2001) \\
Erfurt, Germany & 17,700 & 2270 & Ruuskanen et al. (2001) \\
Helsinki, Finland & 16,200 & 973 & This work \\
Pittsburgh, Urban & 14,300 & 2170 & This work \\
Pittsburgh, Rural & 6500 & 1900 & \\
\hline
\end{tabular}



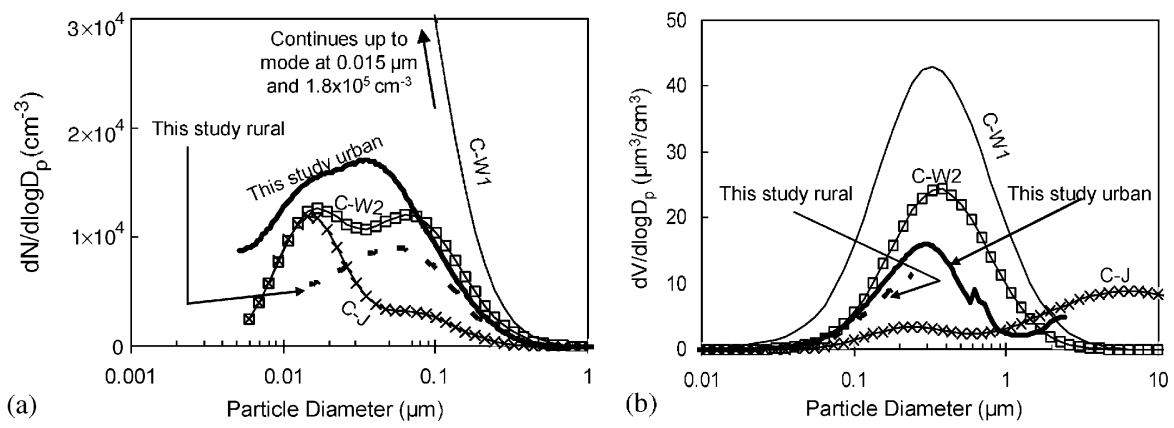

Fig. 9. Comparison of model size distributions to Pittsburgh size distributions on a (a) number basis and (b) volume basis. Model distributions: C-W1 = Whitby (1978) urban average; C-W2 = Whitby (1978) average background; and C-J = Jaenicke (1993) rural continental.

\section{Summary and conclusions}

Twelve months of PM size distributions from the PAQS were summarized. The average Pittsburgh number concentration $(3-500 \mathrm{~nm})$ is $22,000 \mathrm{~cm}^{-3}$ with an average mode size of $40 \mathrm{~nm}$. Seasonal patterns are not very strong for aerosol number, but are clearly evident for the aerosol volume distribution due to the summertime peak in aerosol mass concentrations. Strong diurnal patterns in number concentrations are evident as a direct effect of the sources of particles (atmospheric nucleation, traffic, and other combustion sources). New particle formation from homogeneous nucleation is significant on the $30-50 \%$ of study days and over a wide area (at least a hundred kilometers). Rural number concentrations are a factor of 2-3 lower (on average) than the urban values. Number concentrations are comparable to those found in similar sampling studies in Northern Europe, and model size distributions tested against the PAQS results yield a poor fit between the sampled and model distributions.

The urban and rural PM size distributions measured during the PAQS form an excellent data set for further research on particle sources, nucleation, and aerosol processes. To date, they have been used to address nucleation (Stanier et al., 2004b), aerosol water content (Khlystov et al., 2004b), and source-receptor relationships (Zhou et al., 2004).

\section{Acknowledgements}

This research was conducted as part of the PAQS which was supported by US Environmental Protection Agency under Contract R82806101 and the US Department of Energy National Energy Technology Laboratory under Contract DE-FC26-01NT41017.

\section{References}

Birmili, W., Wiedensolher, A., Heintzenber, J.,Lehmann, K., 2001. Atmospheric particle number size distribution in central Europe: statistical relations to air masses and meteorology. Journal of Geophysical Research 106 (D23), 32,005-32,018.

Cabada, J.C., Takahama, S., Khlystov, A.Y., Wittig, B., Pandis, S., Rees, S., Davidson, C.I., Robinson, A.L., 2004. Mass size distributions and size resolved chemical composition of fine particulate matter at the Pittsburgh Supersite. Atmospheric Environment, this issue, doi:10.1016/j.atmosenv.2004.03.004.

Cheng, M.D., Tanner, R.L., 2002. Characterization of ultrafine and fine particles at a site near the Great Smoky Mountains. Atmospheric Environment 36, 5795.

Donaldson, K., MacNee, W., 1998. The mechanism of lung injury caused by $\mathrm{PM}_{10}$. In: Hester, R.E., Harrison, R.M. (Eds.), Issues in Environmental Science and Technology. The Royal Society of Chemistry, London.

Harrison, R.M., Shi, J.P., Jones, M.R., 1999. Continuous measurements of aerosol physical properties in the urban atmosphere. Atmospheric Environment 33, 1037-1047.

Jaenicke, R., 1993. Tropospheric aerosols. In: Hobbs, P.V. (Ed.), Aerosol-Cloud-Climate Interactions. Academic Press, San Diego, CA, pp. 1-31.

Khlystov, A., Stanier, C., Pandis, S.N., 2004a. An algorithm for combining electrical mobility and aerodynamic size distribution data when measuring ambient aerosol. Aerosol Science and Technology, in press.

Khlystov, A., Stanier, C., Takahama, S., Pandis, S.N., 2004b. Water content of ambient aerosols during the Pittsburgh Air Quality Study. Journal of Geophysical Research, submitted for publication.

Kikas, U., Mirme, A., Tamm, E., Raunemaa, T., 1996. Statistical characteristics of aerosol in Baltic sea region. Journal of Geophysical Research 101 (D14), 19,319-19,327.

Kim, S., Shen, S., Sioutas, C., Zhu, Y., Hinds, W., 2002. Size distributions and diurnal and seasonal trends of ultrafine particles in source and receptor sites of the Los Angeles basin. Journal of the Air and Waste Management 52, 297-307. 
Lippmann, M., Ito, K., Nádas, A., Burnett, R.T., 2000. Association of particulate matter components with daily mortality and morbidity in urban populations. Research Report 95, Health Effects Institute, Cambridge, MA.

Meyer, M.B., Patashnick, H., Ambs, J.L., Rupprecht, E., 2000. Development of a sample equilibration system for the TEOM continuous PM monitor. Journal of the Air and Waste Management 50 (8), 1345-1349.

Morawska, L., Jayarantne, E.R., Mengersen, K., Thomas, S., 2002. Differences in airborne particle and gaseous concentrations in urban air between weekdays and weekends. Atmospheric Environment 36, 4375-4383.

Oberdorster, G., Ferin, J., Gelein, R., Soderholdm, S.C., Finkelstein, J., 1992. Role of alveolar macrophage in lung injury; studies with ultrafine particles. Environmental Health Perspectives 102, 173-179.

Oberdorster, G., Gelein, R.M., Ferin, J., Weiss, B., 1995. Association of particulate air pollution and acute mortality: involvement of ultrafine particles. Inhalation Toxicology 7 , 111-124.

Ruuskanen, J., Tuch, Th., Ten Brink, H., Peters, A., Khystov, A., Mirme, A., Kos, G.P.A., Brunekreef, B., Wichmann, H.E., Buzorius, G., Vallius, M., Kreyling, W.G., Pekkanen, J., 2001. Concentrations of ultrafine, fine and $\mathbf{P M}_{2.5}$ particles in three European cities. Atmospheric Environment 35, 3729-3738.

Samet, J.M., Zeger, S.L., Dominici, F., Curriero, F., Coursac, I., Dockery, D.W., Schwartz, J., Zanobetti, A., 2000. The National Morbidity, Mortality, and Air Pollution Study, part II: morbidity and mortality from air pollution in the United States. Research Report 94, Health Effects Institute, Cambridge, MA.

Shi, Q., 2003. Aerosol size distributions ( $3 \mathrm{~nm}$ to $3 \mu \mathrm{m})$ measured at the St. Louis Supersite (4/1/01-4/30/02). M.S. Thesis, Department of Mechanical Engineering, University of Minnesota, Minneapolis, MN 55455.
Stanier, C. 2003. Dry-ambient aerosol size spectrometer data quality statement. NARSTO Quality Systems Science Center, Website, http://eosweb.larc.nasa.gov/PRODOCS/ narsto/table_narsto.html\#epa.

Stanier, C., Khlystov, A., Chan, W.R., Mandiro, M., Pandis, S.N., 2004a. A method for the in situ measurement of fine aerosol water content of ambient aerosol: the dry-ambient aerosol size spectrometer (DAASS). Aerosol Science and Technology, in press.

Stanier, C., Khlystov, A., Pandis, S.N., 2004b. Nucleation events during the Pittsburgh Air Quality Study: description and relation to key meteorological, gas phase, and aerosol parameters. Aerosol Science and Technology, in press.

Whitby, K.T., 1978. The physical characteristics of sulfate aerosols. Atmospheric Environment 12, 135-159.

Wichmann, H.-E., Peters, A., 2000. Epidemiological evidence of the effects of ultrafine particle exposure. Philosophical Transactions of the Royal Society A 358, 2751-2769.

Wichmann, H.-E., Spix, C., Tuch, T., Wölke, G., Peters, A., Heinrich, J., Kreyling, W.G., Heyder, J., 2000. Daily mortality and fine and ultrafine particles in Erfurt, Germany. Part I: role or particle number and particle mass. Research Report 98, Health Effects Institute, Cambridge, MA.

Wittig, B., Anderson, N., Khlystov, A.Y., Pandis, S.N., Davidson, C., Robinson, A.L., 2004. Pittsburgh Air Quality Study overview. Atmospheric Environment, this issue, doi:10.1016/j.atmosenv.2004.03.003.

Woo, K.S., Chen, D.R., Pui, D.Y.H., McMurry, P.H., 2001. Measurement of Atlanta aerosol size distributions: observations of ultrafine particle events. Aerosol Science and Technology 34, 75-87.

Zhou, L., Kim, E., Hopke, P.K., Stanier, C., Pandis, S.N., 2004. Advanced factor analysis on Pittsburgh particle size distribution data. Aerosol Science and Technology, in press. 